\title{
CONSIDERATION OF NONSTEADY STATE CRACK GROWTH IN MATERIALS EVALUATION AND DESIGN
}

\author{
S. J. HUDAK, Jr. \\ Westinghouse Electric Corporation, Research and Development Center, \\ 1310 Beulah Road, Pittsburgh, Pennsylvania 15235, U.S.A. \\ R. P. WEI \\ Lehigh University, Department of Mechanical Engineering and Mechanics, \\ Bethlehem, Pennsylvania 18015, U.S.A.
}

SUMMARY

Fracture mechanics is belng used Increasingly in the design and rellability assurance of reactor pressure vessels. This technology enables a quantitative assessment of the potential influence of environment enhanced crack growth on vessel integrity. The basis of such an assessment is a one-to-one relationshlp between the rate of crack growth and $\mathrm{K}$, the applied value of crack-tip stress intensity factor. The purpose of this work 1 s to examine the uniqueness of this relationship and also to elucidate and assess the significance of any deviations from such a relationship.

Data on a varlety of low alloy steels, exposed to aqueous environments, are presented which demosntrate that under certain conditions the $K$ versus growth rate relationship appears not to be unique - that $1 s$, for a glven value of $\mathrm{K}$, several distinctly different rates can occur. Tests conducted under both static and cyclic loading are shown to exhlbit this behavior following test start-up, test interruptions, or changes in loading varlables such as cyclic frequency. In order to understand this phenomenon, experiments were conducted on a quenched and tempered low alloy steel exposed to distllled water. Using specimens in which $\mathrm{K}$ remalns constant, as the crack grows under constant $10 a d$, data have been obtained which demonstrate that this behavior is due, at least in part, to nonsteady state crack growth. Initially rates are signiffcantly less than the steady state rate, and although crack growth eventually accelerates to the steady state rate, significant transient periods occur. A unfque, geometry independent relationship only exists between crack growth rates and crack-tip stress intensity factor provided these nonsteady state effects are eliminated.

For a given materfal, the duration of this transient period appears to be dependent on environment chemistry, thereby suggesting that the phenomenon 1s controlled by the kinetics of underlytng chemical processes which lead to the materlal's degradation. A kinetic model based on the concept of a hydrogen embrittled volume of materfal at the crack t1p provides a unifled understanding of the various transient behavior in the steels considered herein.

The practical significance of this time dependent behavior is that 1 t can cause laboratory data to misrepresent the growth rates which occur under operating conditions in reactor pressure vessels. Recommendations are provided for Identifying these nonsteady state effects when acquiring laboratory data. Approaches to dealing with transient crack growth rates in design and rellabllity assessments are also outlined. 


\section{Introduction}

Much work is currently underway to assess the influence of reactor water environments and applied loading varlables on the fatlgue crack growth behavior of nuclear pressure vessel and piping materlals. Recent papers have summartzed this effort [1,2]. Because this information is needed for design and rellabllity assurance of reactor components, basic fatigue crack growth rate data are being generated within the framework of linear elastic fracture mechanics: The basis of this fracture mechanics approach is a one-to-one relationship between the rate at which cracks grow and the mechanical "driving force" which is characterized in terms of the crack-tip stress intensity factor.

The objective of this paper is to critically examine the uniqueness of this fundamental relationship. In so dolng, a varlety of crack growth rate phenomena - primarily assoclated with test start-up, test Interruptions and changes in loading varlables - whlch have heretofore been labeled anomalous are reviewed and discussed. An attempt is made to provide a general explanation of these results in terms of underlylng kinetic mechanlsms. Examples are drawn from both static and cyclic crack growth in low alloy ferritic and martensitic steels exposed to a varlety of aqueous environments. Although cyclic loading is of paramount Importance to pressure vessel and piping applications, crack growth under static loading 1s also presented to examine the general nature of these phenomena. The practical significance of these phenomena to materials evaluation and design is also discussed.

\section{Crack Growth Under Stat1c Loading}

Static-load crack growth rates as of function of applied stress intensity factor, $K$, for a 4340 steel exposed to room temperature dist1lied water are shown in F1g. I [3]. As is typical for environment induced, static crack growth, these results exhibit two distinctly different regimes - in Stage I the rates are strongly dependent on $\mathrm{K}$, while in Stage II the rates become independent of $\mathrm{K} .^{*}$ The $\mathrm{K}$-Independent rate in Stage II results from a rate limfing process which has been ldentifled as the slow, second step of the surface reaction of $\mathrm{H}_{2} \mathrm{O}$ and clean fracture surfaces [11]. This reaction produces the hydrogen required for subsequent embrittlement.

However, of greater 1mportance for our purposes here is the fact that different Stage I curves were observed upon conducting experfments at different inftial stress intensity factors, $K_{1}$. As a result, for a glven value of applied $K$, a variety of different growth rates occur. Thus, the practical question arises as to which Stage I curve 1s appropriate for use in materials evaluation and design? Furthermore, the fact that the da/dt versus $\mathrm{K}$ relationship is nonunique would appear to violate a basic tenent of the fracture mechanics approach to environment Induced cracking.

In order to shed some light on this apparent dilemma, the authors' have generated some data under constant-K conditions, enabling crack growth rates to be solely examined as a function of time [4]. These results were obtalned using a constant applied load and the constant-K spectmen 1llustrated in Fig. 2; the materlal and environment were the same as those of Ref. [3] and FIg. 1.

As shown in F1g. 2, the growth rates were found to change inftially with time over a perlod of about 20 minutes. Durlng this translent, or nonsteady state perlod, the crack

\footnotetext{
* A third regime, Stage III, where rates again become strongly K-dependent as mechanical instabilfty is approached, was not measured in these particular expertments.
} 
growth continued to accelerate unt1l finally a rate was established which was no longer time dependent - that is, a steady state rate was achleved. These steady state rates are 1n good agreement with the uppermost data $1 \mathrm{~F}$ FIg. 1 at $\mathrm{K}$ values of $21 \mathrm{MPa} \sqrt{\mathrm{m}}$ and $30 \mathrm{MPa} \sqrt{\mathrm{m}}$. It follows that the rates in FIg. I which are below the solld curve (defined by the uppermost data) are influenced by nonsteady state behavior. Therefore, the nonuniqueness of the Stages I rates in F1g. 1 appears not to be due to the different initially applied stress intensity conditions per se, but rather to the inftial time dependency of the growth rates following loading. The agreement between the steady state rates generated from center cracked panel spec1mens (F1g. 1) and tapered double cantilever beam spec1mens (F1g. 2) clearly demonstrates that a unfque, geometry-1ndependent relationship exists between da/dt and $\mathrm{K}$, provided steady-state condtions prevall.

\section{Crack Growth Under Cyclic Loading}

Since the aforementioned nonsteady state crack growth rate behavior appears to be inextricably assoctated with the presence of the aggressive environment, one might expect to observe the same behavior under cyclic as well as static loading. This in fact appears to be the case based on recently observed environment enhanced fatigue crack growth rate data.

Results from Scott on a structural steel exposed to natural seawater at room temperature provide a clear example of this behavior as shown In FIg. 3 [5]. These experiments, whtch were conducted at a test frequency of $0.1 \mathrm{~Hz}$ and a load ratio ( $\mathrm{R}=\mathrm{min}$ imum load/maximum load) of 0.5 , result in about a factor of three enhancement in the fatigue crack growth rates relative to rates measured in laboratory air. Moreover, the growth rates show a dependence on the 1nitially applied stress intensity range, $\Delta \mathrm{K}_{1}$, which is analogous to the static-load growth rate behavior of $\mathrm{Fig}$. 1 .

Similar behavior has been reported by Bamford, et al. for pressure vessel steels exposed to a pressurfzed water reactor environment at $560^{\circ} \mathrm{K}$ [6]. However, in this case the transient growth rates following inftlal loading were of slgnificantly longer duration. In fact, data from some tests started at high $\Delta \mathrm{K}$ values never achleved the higher growth rates established during separate tests started at lower $\Delta \mathrm{K}$ values. Since these tests were conducted at cyclic frequencles on the order of $0.01 \mathrm{~Hz}$, transient perlods were on the order of thousands of hours. These results clearly indicate that the magnitude of the transient perfod is a strong function of the matertal-environment system.

Transient growth rate behavior is not limfted to the period following initial commencement of fatigue loading - transient periods have also been observed following test interruptions and changes in loading vartables such as cyclic frequency.

Figure 4 shows the effect of an overnight test stoppage on the crack length versus elapsed cycle curve for a center-cracked-panel spectmen of 4340 steel exposed to distilled water at room temperature [7]. A transient growth rate perlod, introduced by the test interruption at about 3000 cycles, 1s manifested by a sharp change in slope of the measured curve. The dashed curve 1llustrates the behavior which would be expected had the 1nterruption not occurred. As indicated in Fig. 4, the slope of the curve eventually returns to the expected steady state growth rate following a transtent period of about 3000 cycles. It is relevant to note that this specimen was cleaned and dried immediately following the Interruption of cyclic loading, thus the observed transient la not attributable to a temporary blunting of the crack-tip by general corroglon during the teat stoppage. 
An example of the effect of a test interruption on the da/dN versus $\Delta \mathrm{K}$ curve is provided by data of Bamford and Ceschinl shown 1n F1g. 5 [8]. This particular fatigue crack gorwth rate test, 1nvolving a pressure vessel steel exposed to a pressurfzed water reactor environment, was Interrupted for 10 days during which time the specimen was removed from the environment and thereby allowed to dry. Crack growth rates measured immediately following the test interruption were four times slower than those 1mmediately preceding the interruption. Moreover, subsequent fatigue cycling never achleved the steady-state growth rates established using other uninterrupted specimens. Interestingly, the retarded growth rates measured after the interruption were the same as those obtained by starting a new test at a $\Delta \mathrm{K}$ value of $33 \mathrm{MPa} \sqrt{\mathrm{m}}$. Therefore, the 1mplication 1 s that the transient growth rates assoclated with different Inftlal test starting conditions, and those associated with test Interruptions, are one and the same phenomenon.

Transient growth rates can also be produced by changes in cycllc loading history other than test interruptions. For example, the fatigue crack growth rates in 4340 steel exposed to water vapor which are given in Fig. 6, clearly show a region of transient growth rates following a change in cyclic frequency from $10 \mathrm{~Hz}$ to $0.1 \mathrm{~Hz}$ [9]. The faster, steady state rates corresponding to $0.1 \mathrm{~Hz}$ were eventually established after $0.1 \mathrm{~cm}$ of crack growth. Translent responses in the opposite direction were also observed after 1ncreases in the cyclic frequency. Since growth rates in inert environments are not influenced by changes in cyclic frequency, these results must result from material-environment interactions.

\section{Discussion}

The aforementioned growth rate phenomena are belleved to be related in that all are primar1ly caused by nonsteady state growth which is controlled by underlying kinetic processes in the material-environment interaction. Th1s concept provides a consistent view of transient growth rates assoclated with test start-up, test interruptions and changes In cyclic frequency and is supported by the following evidence.

First, nonsteady state growth rates have been measured for environment induced crack growth under static load and shown to be the cause of the dependence of Stage I growth rates on the initially applied stress Intensity factor. In addition, when the nonstady state effects are elfminated, a unfque geometry-independent relationship exists between da/dt and $K$.

Secondly, the duration of the transient perfod is strongly dependent on environtment. For example, FIg. 7 shows fatigue crack growth rate data on a pressure vessel steel exposed to a $\mathrm{H}_{2} \mathrm{~S}$ environment which demonstrates the absence of any measurable transient associated with four separate tests each conducted at different inftial $\Delta \mathrm{K}$ values [10]. This steel is for all practical purposes Identical to that of Flg. 5 which, when exposed to a pressurized water environment, exhlbits large transient pertods, both on inftlal test start-up and following test interruptions. In general, this difference in transient response for essentially identical material exposed to different environments is understandable if one considers that the detalled kinetic processes which are essential for environment enhanced crack growth can differ greatly for dffferent environments. For example, basic surface chemistry studies have established that the rate limiting step in the reaction of $\mathrm{H}_{2} \mathrm{~S}$ with steel 1s about $10^{9}$ times faster than the corresponding step in the reaction of water vapor with steel [11,12]. The relative insensitivity of fatigue crack growth rates in $\mathrm{H}_{2} \mathrm{~S}$ to cyclic frequency, except at very low pressures, attests to these rapid kinetics. Th1s 
behavior is in contrast to the strong frequency and waveform dependency of fatigue crack growth rates when this same steel is exposed to pressurized water [1].

Finally, the fact that transients occur after changes in cyclic frequency - an Important varlable for crack growth in aggressive environments, but not for growth in inert environments - virtually eliminates an explanation of these phenomena based on purely mechanical events. The long-range nature of the transients also supports this view. The extensive amounts of crack extenston under transient conditions preclude arguements based on crack blunting due to general corrosion, or resldual stress/crack closure due to inadvertent specimen overloading since both of these effects would diminish after relative small amounts of crack extension - on the order of several crack-tip root radil or plastic zone sizes.

Although the above arguements clearly support the concept that the kinetics of underlylng physio-chemical proceases control the observed crack growth rate phenomena, the spectfic mechanism involved is not firmly established. However, some Insight is provided by general kinetlc considerations. Pao, et al. have proposed a kinetic model based on the establishment of a steady state volume (as opposed to surface) of hydrogen damaged material at the crack tip [9]. The embrittled volume ahead of the crack tip would be larger for the slower cyclic frequencles because of the increased reaction time and thus the amount of hydrogen produced per cycle. Thus, as the frequency ts changed the slze of the embrittled volume will change with time according to the governing kinetics and a corresponding translent crack growth rate reaults. Obvlously, this model applies only to materialenvironment systems where the damaging mechanism involves hydrogen embrittlement. However, since hydrogen embrittlement has been 1dentifled as the mechanism for crack growth in steels exposed to water and water vapor, this kinetic model appears viable for the materfalenvironment systems considered herein [1-3].

The model also provides a rationale for the transient crack growth rates which follow Inttlal test start-ups, since time would be required for the volume of hydrogen damage materlal to increase to 1ts steady state size. The transient crack growth rates following test Interruptions can also be explained in a similar fashion, provided an alteration of the crack tip hydrogen concentration, and corresponding damaged volume, can occur during the interruption. This alteration could concelvably occur by bulk diffuston of hydrogen from the crack t1p while the specimen 1s unstressed. Subsequently, the steady state, embrittled volume would have to be reestablished when the test is restarted. Alternatively, 1t is posstble that the size of the embrittled volume could be altered without hydrogen diffusion from the crack tip. In liquid environments, for example, it may require some time to reestablish the proper crack-tip chemical/electrochemical conditions so that sufficlent hydrogen is avallable to malntain the embrittled volume at its former steady state size.

One final point on mechanisms is appropriate. The above kinetic model involving hydrogen embrittlement should not be taken to 1mply that transient crack growth rate phenomena will not occur in materfal-environment systems which crack due to damaging mechanlsms other than those 1nvolving hydrogen. In fact, the occurrence of these transient crack growth rates is expected to be a general phenomenon and would be governed by whatever kinetic processes leads to the damaging effects.

\section{Practical Significance of Tranglent Crack Growth Rates}

Translent growth rate phenomena are of practical significance to: 1) obtaining representative materlals data and 2) formulating realistic degign philosophies. With respect 
to the former, there is a danger assoclated with not recognizing the presence of nonsteady state effects and thereby making improper Inferences about crack growth rates which are presumed to represent steady-state behavior. For example, this can occur when data are generated under K-1ncreasing conditions with all tests started at the same $\Delta \mathrm{K}$ value. The sharply accelerating fatigue crack growth caused by Initial transient behavior could be misinterpreted as defining the threshold stress intensity condition required for environment enhanced crack growth. The presence of such nonsteady state behavior can be 1 dentiffed by performing $\mathrm{K}-1 \mathrm{ncreasing}$ tests at different starting $\Delta \mathrm{K}$ levels. These transients can also be more directly Identifled by conducting constant $\Delta \mathrm{K}$ tests analogous to those used to obtain the static load data in Fig. 2. The advantage of the constant $\Delta \mathrm{K}$ test is that $1 \mathrm{t}$ can unequivocally define the steady-state rate at a given $\Delta \mathrm{K}$ value; the disadvantage 1 s that many more tests are required to define the $d a / d N-\Delta K$ curve.

Translent crack growth rates are significant In design considerations since most applications Involve interruptions to the typical load history due to operation shutdowns - these being equivalent to test interruptions. As 11lustrated by data in F1g. 5, these shutdowns can have a significant impact on the environment enhanced fatigue crack growth rates. Currently no methodology exists for incorporating these transient effects into design and reliability conslderations. One could take the approach that transients should be eliminated from laboratory generated data, and that designs be based on steady state fatigue crack growth rates. Th1s approach would add conservatism to the design - perhaps to an unrealistic extent - since under certain conditions shutdowns could retard the fatigue crack growth rates relative to the steady-state rates. The task of Incorporating expected transient growth rate behavior 1nto design and reliablitty considerations in a quantitative manner appears formidable from two vlewpoints: (1) Much information would be needed to determine the shutdown conditions which strongly influence the transients. For example, must the environment be removed, and for how long, to induce a transient? (2) In order to take advantage of the retarded growth rates, detalled Information would be required about the anticlpated or experfenced shutdown history for design and reliability assessments, respectively.

\section{References}

[1] BAMFORD, W. H., MOON, D. W., "Some Mechanistic Observations on the Crack Growth Characterlstics of Pressure Vessel and PIping Steels in PWR Environment," Corrosion 79, NACE Meet1ng, Atlanta, GA, March 1979.

[2] HALE, D. A., KASS, J. N., "Fatigue Crack Growth of Low Alloy Steel in a High Temperature, High Purity 0xgenated Water Environment," 1bid.

[3] LANDES, J. D., WEI, R. P., "The Kinetics of Subcritical Crack Growth Under Sustained LoadIng," Int. J. of Fracture, 9, (3), pp. 277-293 (1973).

[4] HUDAK, S. J., Jr., WEI, R. P., unpublished results, 1972.

[5] SCOTT, P. M., SILVESTER, D. R. V., "The Influence of Mean Tensile Stress on Corrosion Fatigue Crack Growth in Structural Steel Immersed in Sea Water," Tech. Rep. UKOSRP 3/02, Harwell Corroston Service, UKAEA (May 1977).

[6] BAMFORD, W. H., MOON, D. M., CESCHINI, L. J., "Crack Growth Rate Testing in Reactor Pressure VesseI Steels," Proc. of 5th Water Reactor Safety Inf. Mtg., Gaithersburg, MD (November 1977). 
[7] MILLER, G. A., HUDAK, S. J., Jr., WEI, R. P., "The Influence of Loading Varlables on Environment-Enhanced Fatigue Crack Growth In High Strength Steels," J. of Testing and Eva1., JTEVA, 1, (7), Pp. 524-531, (1973).

[8] BAMFORD, W. H., CESCHINI, L. J., "Effects of H1gh Temperature Primary Reactor Water on Fatigue Crack Growth of Reactor Vessel Steels," In HSST Quart. Prog. Rep. ORNL-NUREGTM-194, Pp. 25-35 (May 1978).

[9] PAO, P. S., WEI, W., WEI, R. P., "Effect of Frequency on Fatigue Crack Growth Response of AISI 4340 Steel in Water Vapor," Symp. on Environment Sensitive Fracture of Engineering Materlals, AIME mtg., Ch1cago, IL (October 1977).

[10] BAMFORD, W. H., CESCHINI, L. J., "Effects of High Temperature Primary Reactor Water on Fat1gue Crack Growth of Reactor Vessel Steels," In HSST Quart. Prog. Rep. ORNL-NUREGTM-209, pp. 6-11, (July, 1978).

[11] SIMMONS, G. W., PAO, P. S., WEI, R. P., "Fracture Mechanics and Surface Chemistry Studies of Subcritical Crack Growth in AISI 4340 Steel," Met. Trans,, (9A), pp. 11471158 (August 1978).

[12] WEIR, T., Lehigh University, Bethlehem, PA, prlvate communlcation, February 1979.

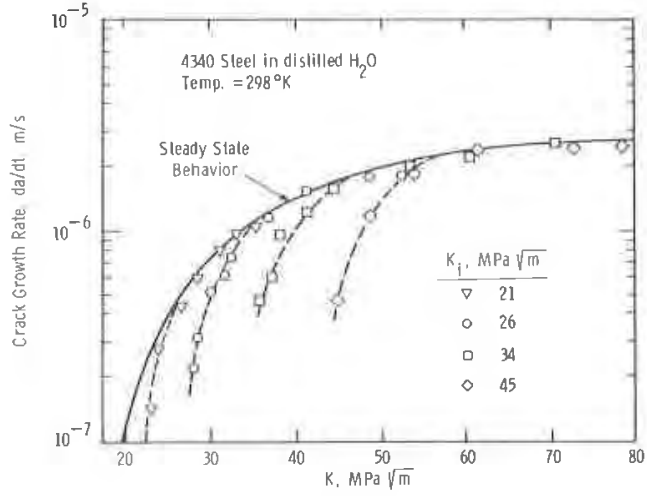

Fig. 1 - Dependence of static-load crack growth kinetics on inltially applled stress Intensity factor, $\mathrm{K}_{1}$

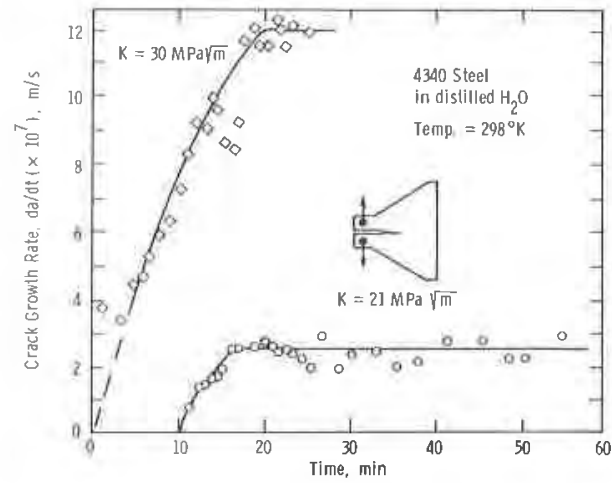

Fig. 2 - Static-load crack growth rates under constant stress Intensity factor conditions showing transient and steady-state behavior

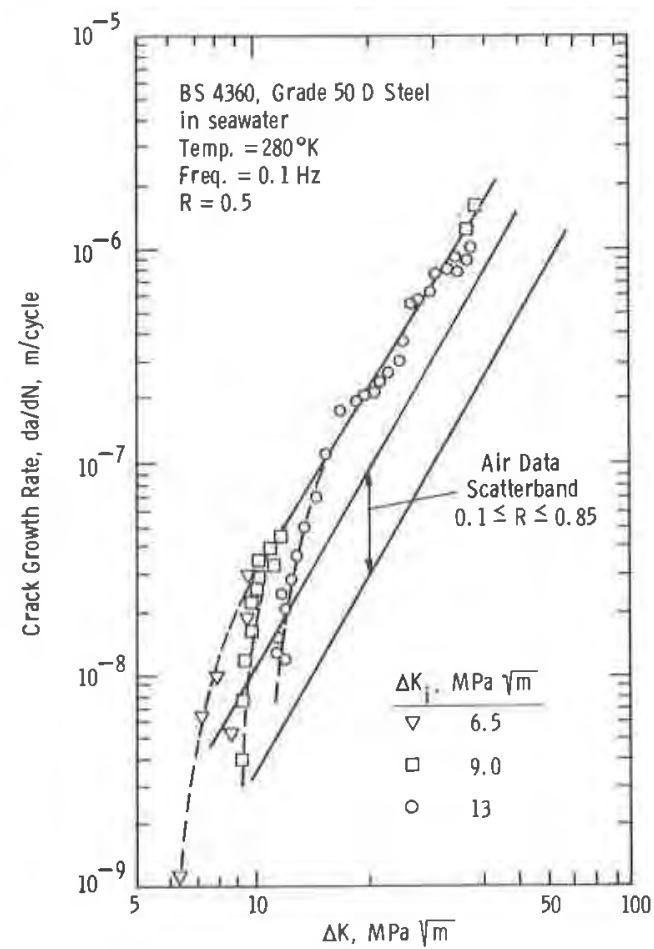

F1g. 3 - Dependence of fatigue crack growth k1netics on initlally applied stress intensity factor range, $\Delta \mathrm{K}_{1}$ 


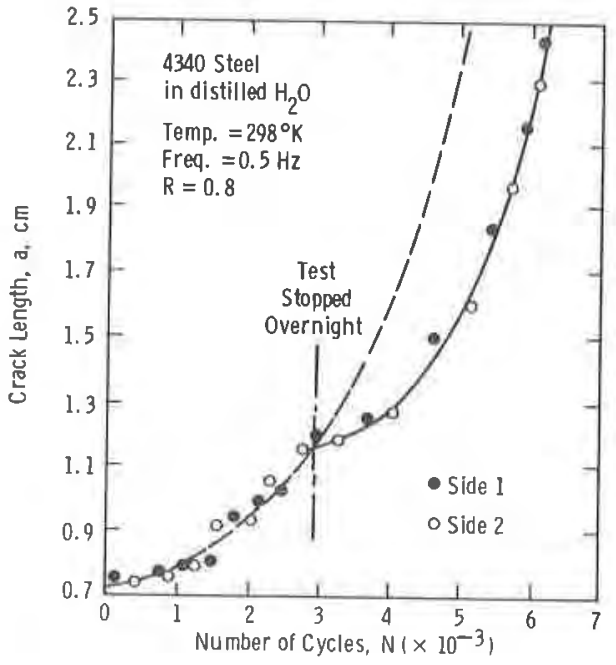

F1g. 4 - Effect of teet 1nterruption on the crack length versus elapsed cycles curve for fatigue loading

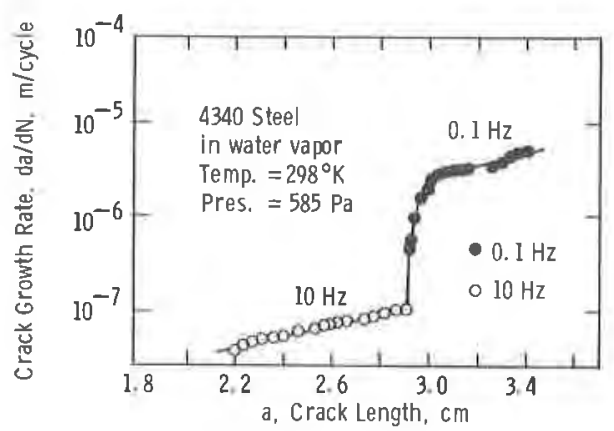

F1g. 6- Fatigue crack growth rate response resulting from a change in cyclic loading frequency

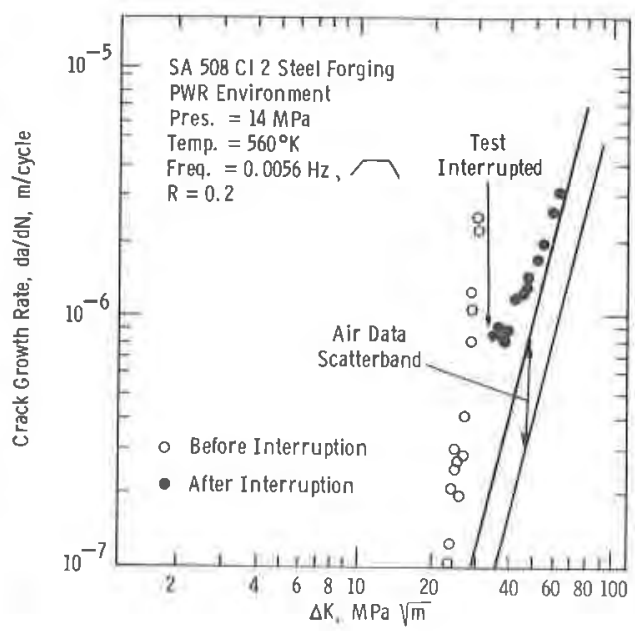

F1g. 5 - Effect of test Interruption on fatigue crack growth kinetics

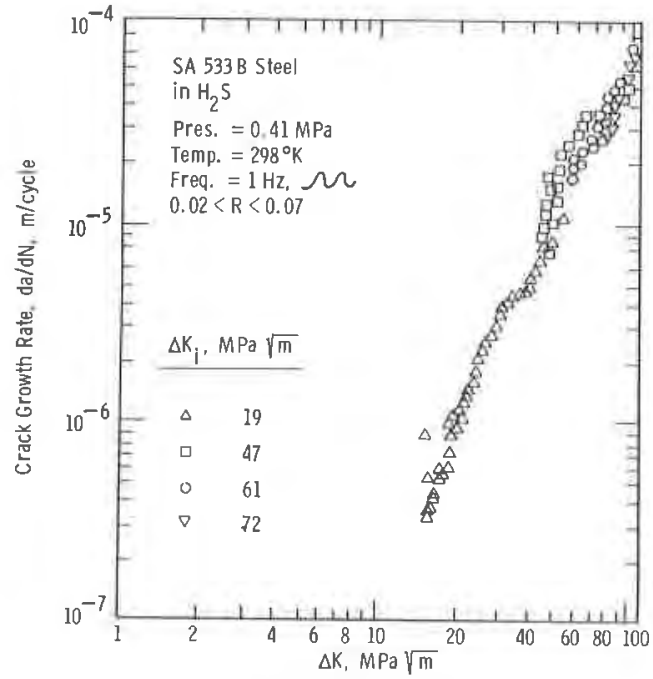

FIg. 7 - Independence of fatigue crack growth kinetics in $\mathrm{H}_{2} \mathrm{~S}$ on inftially applied stress intensity factor range, $\Delta \mathrm{K}_{1}$ 